equation of motion of the particle. He showed that the rules of quantization were automatically obeyed. The subsequent generalization and wide application of Schrödinger's wave mechanics proved remarkably successful, but there were limitations. One-electron problems or problems with separable variables could be dealt with ; but the equations for $\mathrm{H}_{2}$, the simplest molecular problem, or for the reaction $\mathrm{H}+\mathrm{H}_{2} \rightarrow$ $\mathrm{H}_{2}+\mathrm{H}$, which is the simplest three-electron problem of chemical interest, to say nothing of the more complicated problems of large molecules, are insoluble. These severe limits to the complete calculation of almost any single physical or chemical property led to considerable despondency, and this despondency, it is Dr. Coulson's belief, is due to a wrong conception of the true function of wave mechanics. "Wave mechanics", to quote Dr. Coulson, "is the key-or perhaps $a$ key-to the future of physics, chemistry and biology. However, when we open doors with it we do not find completely worked out, neat solutions to all our problems, but new ideas, new principles, new understanding of processes the details of which we shall probably never calculate to 'so many' significant figures, and new relations between apparently unrelated properties."

The examples chosen by Dr. Coulson to illustrate his meaning are taken from fields in which he has made important contributions. They include: atomic and molecular structure, referring briefly to stereochemistry, and to the structure of benzene, which introduces the general phenomenon of 'resonance' and the idea of fractional bond order; electrons in metals, and the understanding of conduction, photo-conduction, fluorescence, etc., which has resulted from the idea of bands of energy-levels but without the band distribution of any single metal ever having been completely calculated; colour; chemical reactions; and finally, the very large molecules from which the nature of life may be determined.

\section{THE HATHERLY BIOLOGICAL LABORATORIES, UNIVERSITY COLLEGE, EXETER}

\author{
BY Prof. JOHN CALDWELL
}

$\mathrm{T}$

WE foundation stone of the Hatherly Biological Laboratories of the University College of the South-West, Exeter, was recently laid by the Marquess of Salisbury, president of the College, in the presence of representatives of the County, the City and the College. When the building is completed, as it is hoped, within the next two years, it will accommodate the Departments of Botany and Zoology, which are, at present, housed in very inadequate and cramped quarters in the Old College buildings in the centre of the city.

The War has, of course, greatly impeded the development of the College as regards buildings, and the estate which the College acquired some twenty-five years ago affords great opportunity for building development, though inevitably that development must be temporarily delayed. It is fitting, therefore, that the first of the post-war buildings should be for the Biological Departments in a College which serves primarily an essentially agri- cultural area, so that these Departments may have adequate space for the development of their work in the service of the community.

The erection of the Laboratories has been made possible by a bequest of the estate of Mrs. Heath, supplemented by grants from the University Grants Committee. The teaching and research work of the biological departments has expanded very greatly from the time of the appointment of the late J. L. Sager as head of the Department of Biology in the Royal Albert Memorial College in 1907. The scope of the Department increased rapidly right from the beginning, and in 1928 a Department of Zoology was set up under Dr. G. Lapage, who was succeeded on his appointment to Cambridge by Mr. L. A. Harvey, the present head of the Department of Zoology. Mr. Sager continued as head of the Department of Botany until his retirement in 1935 , when he was succeeded by the present writer, who had previously been on the staff of the Department of Plant Pathology at Rothamsted Experimental Station. Both Departments in the College, as is common to all university departments at present, are overerowded and badly in need of additional accommodation.

When the new Laboratories are completed, each Department should have adequate accommodation for reasonable expansion. Each will have three large main laboratories and a small laboratory for honours students, with adequate private rooms, preparation and lecture rooms. There will also be a large lecture room, museum accommodation and dark rooms, tank and constant-temperature rooms for general use.

The building, which is designed by Mr. E. Vincent Harris, is in the form of a main block with private rooms and caretakers' quarters on the front, with five bays running back from it in which are situated the laboratories. This arrangement will allow of the maximum of light being available in the laboratories without having a south exposure.

As the site is on the College estate on the outskirts of the city, there is a considerable amount of ground available behind and around the building, which it is proposed to lay out for botanical collections and experimental ground with glasshouses. The whole should eventually form an ideal unit for biological investigation and teaching. The Departments have now, even under the present conditions, a wide range of research work on hand. On the botanical side, various aspects of virus diseases are being studied, both on the more general side and on diseases of specific erop plants common in the region.

Other phytopathological work includes the study of the ecology of fungi in relation to plant disease, investigation of the Erysiphales, and of the rust of Chrysanthemum and similar studies. The cytology of various plants is being investigated as well as more general cytogenetical subjects. At the same time there is a considerable amount of work being done on the cultivation of various plants of some economic importance, and a study of their anatomy and physiology in relation to different cultural methods. It is hoped also to expand and develop an ecological survey of a portion of Dartmoor.

On the zoological side investigations are being carried out on the ecology of areas in the south-west with special reference to Lundy, on some aspects of parasitic protozoology and on some problems of human fertility. 